\title{
Desconstruindo mitos de origem: a língua portuguesa é um fenómeno tardio que vem do galego e não de fenícios ou de árabes
}

\author{
Deconstructing myths of origin: the Portuguese language \\ is a late phenomenon that comes from Galician and not \\ from Phoenicians or Arabs
}

Vítor Manuel Fernandes Oliveira de Sousa ${ }^{a}{ }^{*}$

VENÂNCIO, Fernando, 2019. Assim nasceu uma língua: Sobre as origens do português. Lisboa: Guerra e Paz.

\begin{abstract}
A História não foi sempre o que nos ensinaram. E nem poderia ser de outra forma, já que a História é uma disciplina que está, tal como todas as outras disciplinas, inserida na sociedade, pelo que nunca poderá ser reificada, ou assumida como um qualquer carimbo que impeça eventuais mudanças. As explicações, por mais desconstrutoras que sejam, são determinantes para se poder perceber o mundo e a História não foge à regra. E, nesse quadro, Portugal leva a palma quando posto em confronto com outros povos. O que não quer dizer que seja mais ou menos nacionalista do que os outros países, naquilo que o conceito está associado à xenofobia, apesar de alguns exemplos que poderiam ser utilizados para atestar essa constatação. Num olhar psicologizante, Eduardo Lourenço refere-se aos portugueses como sendo detentores de uma hiperidentidade que diz dever-se a um deficit de identidade real que compensam no plano imaginário. O que - ainda navegando nas mesmas águas -, Agostinho da Silva justificou com a situação geográfica do país que, por ser periférico, terá sentido o apelo do mar, porque na sua perspetiva, a vida por cá se tornara asfixiante. E, também, por ser pequeno. Talvez por isso é que o Estado Novo tenha propalado exatamente o contrário, fazendo esvoaçar a bandeira que ia desde o Minho até Timor, sublinhando uma alegada "portugalidade" e a grandiosidade em termos territoriais que o diferenciava dos demais países. Mesmo que isso só tivesse acontecido pela necessidade de combater as forças libertadoras das então colónias (denominadas de províncias) e evidenciar à ONU que esses territórios não eram autónomos, pertencendo a Portugal (Sousa, 2017).
\end{abstract}

\footnotetext{
a Centro de Estudos de Comunicação e Sociedade, Universidade do Minho, Braga, Portugal.

* Correspondência para/Correspondence to: Vítor de Sousa. Endereço: Centro de Estudos de Comunicação e Sociedade, Gabinete 1.42, Edifício dos Congregados, 4710-370 Braga, Portugal. E-mail: vitordesousa@ics.uminho.pt.

Recebido em/Received: 23/06/2021; Aprovado em/Approved: 28/09/2021.
}

Artigo publicado em acesso aberto sob licença CC BY 4.0 Internacional ()(i) 
O livro Assim nasceu uma língua. Sobre as origens do português, de Fernando Venâncio (Guerra e Paz), dá um contributo para essa desconstrução. Um trabalho pioneiro de um linguista, escritor, tradutor e crítico literário que nasceu no Alentejo, foi professor universitário na Holanda até se reformar e regressar a Mértola. O autor conta-nos a história da língua portuguesa com rigor e de forma acessível, sublinhando a diversidade da língua, o que reputa como um facto muito positivo e onde reside, de resto, a sua força.

A grande ideia do livro, cujo projeto vem do século passado, é que a nossa língua veio de fora e foi criada antes de haver Portugal, sendo que o castelhano sempre a contaminou e continua a contaminar. $O$ autor diz não ter andado em arquivos atrás de raridades bibliográficas sobre as origens da língua Portuguesa, por não ter tido essa necessidade, uma vez que a informação constante do livro é do domínio público. Para tanto, ajudou o facto de, desde 2014, ter investido no Portal Galego da Língua, no quadro do qual foram mantidos vários debates (Pacheco, 2019, p. 14). Como confidencia na introdução da obra (um escrito extenso, com mais de 30 páginas), desenvolveu um trabalho pioneiro, garantindo ter ido até onde ninguém antes fora. Naquela que pode ser considerada como a obra da sua vida, enfatiza o que tem vindo a ser alvo de uma investigação aturada que assenta na ideia de que o português é um fenómeno historicamente tardio, com proveniência de uma língua única, a par do galego, a que deve muito da sua identidade, mas de que se separou no início do século XV. Ou seja: o idioma que Portugal adotou, mesmo não existindo ainda enquanto país, já tinha feito um grande tirocínio.

Trata-se de um trabalho importante, tanto mais que desconstrói as narrativas mestras tão legitimadas, nomeadamente por alguma produção científica, que contam uma história diferente, fazendo com que se naturalizasse uma realidade falsa: a de que o português vem do fenício ou do árabe. Essa visão a-histórica, é pontuada por esquecimentos e silêncios reveladores desses mecanismos de manipulação da memória coletiva (Le Goff, 1984). Não que nesta problemática não se convoque o imaginário, tanto mais que ele se revela importante num passado distante, em que era necessário dar cola identitária aos territórios. De resto, o imaginário é portador de uma possibilidade de realidade futura, refazendo o real, assumindo-se como uma visão transgressora em relação ao presente. É nesse sentido que o autor aborda a questão do mito como última possibilidade explicativa, mais não sendo, então, do que um conjunto de símbolos e arquétipos, observável através de mitemas, onde são propostas realidades que antes não existiam. Mas, daí a construírem passados inexistentes, vai uma distância intransponível. Fernando Venâncio desconstrói esses mitos.

Como refere José Mattoso (2008), as narrativas fundadoras confundem-se quase sempre com uma história mítica, que é tão insistente e carregada de emotividade e se distancia sobremaneira de uma visão objetiva, por se distanciar dos factos. No caso português, ela incide sobre o destino universal do povo, do seu insondável 'mistério' e da sua irredutível originalidade. Já Hegel (2001) assinalava que a verdade não é estática, resultando da consciência dos momentos contraditórios, atribuindo uma 
importância central à retroatividade no cerne da reflexão dialética, em direção ao conhecimento "absoluto". Talvez por isso, que Fernando Venâncio, a quem foi perguntado qual o personagem que retrataria a Língua Portuguesa, responde sem hesitações: "Uma galdéria”. Justifica com o facto de ela, a língua, "ter andado "por todas as camas: a galega, a castelhana, a francesa...", saindo delas "mais fresca que nunca" (Marques, 2020).

Em entrevista à revista LER, destaca que prevalece uma visão romântica e ideologizada da língua, que associa ao essencialismo, que pouco tem que ver com a História, aglutinando de forma aproveitadora e inventiva o ideário assente no tripé "um país, um povo, uma língua". Por outro lado, o autor debruça-se sobre o caso reintegracionista que reputa de "particularmente grave", nomeadamente quando diz "ver galegos apregoando os mitos portugueses, exatamente negadores do papel fundamental do galego na génese do idioma” (Barriga, 2019, p. 32).

O certo é que, independentemente da sua originalidade "portuguesa", a nossa língua - como todas as outras -, está ligada à história do país, não tendo nascido em 1143, de geração espontânea. A Língua Portuguesa começou a ser ensaiada muito tempo antes da fundação de Portugal, ainda muito antes do Condado Portucalense, corria o ano 600. O que em nada belisca a frase de Pessoa (através do heterónimo Bernardo Soares), convertida num verdadeiro soundbyte, de que "a minha pátria é a língua portuguesa". Que, mais tarde, Mia Couto acertaria para "a minha pátria é a minha língua portuguesa”. Mas que lhe dá, sem dúvida, outro contexto. Fernando Venâncio refere que "a fixação na denominação lusitana (ainda hoje a vemos no conceito lusofonia) surgiu quando a Galiza passou para segundo plano, e Portugal procurou uma referência mais a sul, o que foi consagrado por Camões" (Pacheco, 2019, p. 15).

Como observa, no ano de 1100, altura em que Portugal surgiu como entidade política, há já alguns séculos que na Galécia Magna (que, na atualidade, corresponderá aos territórios do Minho e do Douro Litoral), uma língua estava já em uso. Ainda não tinha nome, o que na altura era muito comum, sendo identificada como um falar à moda dos galegos. Foi utilizada na oralidade até 1180 e, a partir daí, começou a escrever-se. Não se tratava, no entanto, de uma língua nova, possuindo já alguma complexidade, tendo um vasto vocabulário próprio (derivado de um latim local) e possuía uma desenvolvida morfologia e uma feição fonológica característica.

Toda a oralidade e otimização do discurso se desenvolveu até à criação de Portugal, altura em que a língua começa a ser escrita o que, segundo o autor, evidencia o lado perverso do processo, que reporta de fortuito e que está associado à ideia de que foram os portugueses os criadores do idioma. O que não corresponde à verdade e que, até agora, muito poucos se mostraram interessados em corrigir (continuando a associá-la aos fenícios e aos árabes, alimentando um mito) sendo certo que, só no século XV, com a Dinastia de Avis, começou a chamar-se de língua portuguesa. Mesmo que se diferenciasse nas várias regiões "portuguesas" e fosse alvo de inovações decorrentes da integração de expressões árabes. 
A retórica "portuguesa" foi sempre sublinhando a sua "originalidade" linguística, olhando para o galego como um seu sucedâneo e não o contrário. O que se percebe, atendendo à fragilidade de fronteiras da época, com os países ainda em formação, tentando colmatar alguma falha identitária através da língua. Ainda mais tratando-se de países vizinhos em que a tensão era grande, mas ao mesmo tempo, havia um fio condutor social decorrente das trocas dos povos que aí viviam. É por isso que Fernando Venâncio refere que "a história do português (...) é "em larga medida, a história das suas tentativas de afastamento do galego" (p. 114), chamando a atenção para o facto de "denominar português qualquer variedade linguística anterior a 1400 [significa] resvalar num anacronismo, e pelo menos numa sofrível incongruência" (p. 83).

O facto é que os portugueses falam português, não fazendo muito sentido mudar o nome à língua, mesmo depois da investigação do autor que evidencia que não devia assustar os portugueses que se exprimam "numa variante do galego" (Barriga, 2019, p. 36). E, pelo que se observa da Região Autónoma da Galiza, há um interesse político em associar-se à Língua Portuguesa, mesmo que ela tivesse nascido no seu próprio território, parecendo não haver complexos a esse respeito. A atestá-lo, está o facto de o parlamento galego ter aprovado, por unanimidade, uma lei que entrou em vigor em 2014, que obriga o Governo da região a introduzir o português no ensino público e a estreitar laços com os países da lusofonia, o que constitui um sinal político fortíssimo no rumo que se pretende seguir em relação à língua. Ou seja: partindo do galego, o português autonomizou-se sendo que, hoje, são os galegos que se dizem faladores de português. O que não deixa de constituir uma grande ironia.

A língua portuguesa está viva e tem futuro, sendo o quarto idioma mais falado no mundo, utilizado por mais de 260 milhões de pessoas com particular destaque nos estados-membros da Comunidade dos Países de Língua Portuguesa (CPLP): Angola, Brasil, Cabo Verde, Guiné-Bissau, Guiné Equatorial, Moçambique, Portugal, São Tomé e Príncipe e Timor Leste. De acordo com projeções das Nações Unidas, em 2050 haverá perto de 400 milhões de lusofalantes, número que crescerá para os 500 milhões no final do século (Reto, Machado \& Esperança, 2016). Por outro lado, o português é a terceira língua do mundo mais utilizada na internet, facto que a valoriza no contexto das novas tecnologias do presente e do futuro (Special Reports - Digital in 2017: Global Overview).

O livro está dividido em quatro partes que evidenciam a cronologia da Língua Portuguesa. A primeira parte intitula-se "Antes do português" (pp. 47-104), em que é abordada "A invenção do galego-português"; na segunda, "Portugal constrói uma língua” (pp. 105-152), preenchida com a temática "Português, língua promíscua”. Segue-se "O Galego e o Português" (pp. 153-254), onde o autor discorre sobre "O léxico exclusivo de galego e português", questiona se "Galego e Português: línguas diferentes?" e aborda a problemática de "O desfiguramento pelo espanhol", terminando com "Sós e acompanhados" (pp. 245-292), onde se debruça sobre "A originalidade do português", "Higienismos e aldrabices" e "Um idioma em circuito aberto". 


\section{REFERÊNCIAS}

BARRIGA, Paulo. Fernando Venâncio: Redescobrir as origens da nossa língua. Revista LER, Lisboa, n. 152, p. 24-36, primavera de 2019.

HEGEL, Georg Wilhelm Friedrich. A Razão na História. São Paulo: Centauro, 2001.

LE GOFF, Jacques. Memória. In Enciclopédia Einaudi, vol. 1, p. 11-50. Lisboa: Imprensa Nacional - Casa da Moeda, 1984.

MARQUES, Joana Emídio. “É promíscua e é liberal”: afinal de onde vem a Língua Portuguesa? Observador, Lisboa, 8 fev. 2020. Disponível em:

<https://observador.pt/2020/02/08/e-promiscua-e-e-liberal-afinal-de-onde-vem-alingua-portuguesa/>. Acesso em: 21 mar. 2020.

MATTOSO, José. A Identidade Nacional. Lisboa: Fundação Mário Soares/Gradiva, 2008.

PACHECO, Nuno. Fernando Venâncio: “O português é um fenómeno tardio". Ípsilon (Público), Lisboa, p. 14-15, 6 dez. 2009.

RETO, Luís, MACHADO, Fernando Luís. \& ESPERANÇA, José Paulo. Novo Atlas da Língua Portuguesa. Lisboa: INCM - Imprensa Nacional Casa da Moeda, 2016.

SOUSA, Vítor de. Da 'portugalidade’ à lusofonia. Famalicão: Húmus, 2017.

Special Reports - Digital in 2017: Global Overview. Disponível em <https://wearesocial.com/special-reports/digital-in-2017-global-overview>. Acesso em: 29 mar. 2020.

VENÂNCIO, Fernando. Assim nasceu uma língua. Sobre as origens do português. Lisboa: Guerra e Paz, 2019. 